\title{
Assessment of Economic Burden due to Alcohol Consumption among Residents of Slum Area of Belagavi City
}

\author{
Khulal R*, Bhatta L, Mubashir A and Narasannavar A \\ Department of Public Health, JNMC, KAHER, India
}

*Corresponding author: Reena Khulal, Post-Graduate Student, MPH, Department of Public Health, JNMC, KAHER, India, Tel: +977-9842442682; Email: reenakhulal@gmail.com

\section{Research Article \\ Volume 3 Issue 6}

Received Date: November 23, 2020

Published Date: December 03, 2020

DOI: $10.23880 /$ jqhe-16000192

\section{Abstract}

Background: Alcohol consumption is an inseparable addiction to all around the world including India in the current scenario. Both direct and indirect cost of the economic burden of alcohol, consumption was estimated to be $0.45 \%-5.44 \%$ of Gross -Domestic Product (GDP). In 2012 alone more than 5.9\% of death has occurred due to alcohol consumption. In India total of $30 \%$ of the total population consumes alcohol, as per census 2011,51.1/100,000 male consume alcohol and 27.1/100,000 female consume alcohol. In India total loss of GDP due to alcohol-related disease is said to be $1.45 \%$ which is Rs 3,127 billion ( $\$ 48.11$ billion) is the economic burden on the health system. Death due to alcohol consumption in India in the year 2012 is 3.3 million. As in India alcohol consumption has increased by 38\% from 2010 to 2017, is from 4.3 liters to 5.9 liters/ adult/ years. In India alcohol is a major source of income from beverage taxes across the country and in case of Karnataka $25 \%$ of the budget is generated for the tax of selling alcoholic beverages.

Methodology: A cross sectional study was conducted in slum areas of Belagavi. The source of data was permanent resident of the slum area Belagavi city who consumes any kind of alcohol beverages. Data collection was done by using pre designed and pre-tested questionnaire. Simple random sampling technique was used for recruiting participants. Total participant were 154 in this study.

Results: out of total participants $29.9 \%$ drink alcohol often. Type of alcohol beverage used were Beer 9\%, wine 6\%, Rum $17.5 \%$ and whiskey $76 \%$. The participants who were guilty of alcohol consumption were $57 \%$ whereas $42.9 \%$ did not feel guilty for consuming alcohol. Significant association was found with the income and amount spent for purchase of alcohol. (P value $=<0.001$ ).

Conclusion: Alcohol consumption has been major problem in the present society. There is significant association found between income and the amount spent for alcohol. As income is directly associated with alcohol consumption.

Keywords: Alcohol; Economic Burden; Alcohol Consumption; Cost

\section{Introduction}

Alcohol consumption is an inseparable addiction to all around the world including India in the current scenario [1]. Globally in 2005 consumption of pure alcohol from age group 15 years and above is 6.13 liters where per person alcohol consumption is $28.6 \%$ which is 1.76 liters. Both direct and indirect cost of the economic burden of alcohol, consumption was estimated to be $0.45 \%-5.44 \%$ of Gross -Domestic Product (GDP). In 2012 alone more than 5.9\% of death has occurred due to alcohol consumption. In India total of $30 \%$ of the total population consumes alcohol, as per census 2011, 51.1/100,000 male consume alcohol and $27.1 / 100,000$ female consume alcohol. In India total loss of GDP due to alcohol-related disease is said to be $1.45 \%$ which is Rs 3,127 billion ( $\$ 48.11$ billion) is the economic burden on 
the health system. Death due to alcohol consumption in India in the year 2012 is 3.3 million [2]. Globally per years the total volume of alcohol consumption has increased by $70 \%$ from 20,999 million liters in 1990 to 35,676 million liters in 2017. According to WHO, in India the heavy episodic drinking between 15 to 19 years is in male and $24.6 \%$ in female overall, whereas more than $44.4 \%$ of alcohol consumer is over 15 years of age [3]. In India alcohol is a major source of income from beverage taxes across the country and in case of Karnataka $25 \%$ of the budget is generated for the tax of selling alcoholic beverages [3]. There are various and all most all types of alcoholic beverages available in the urban Indian market such as Rum, Whiskey, Scotch, etc. However in the rural sector it mainly compromises the same beverages types with lesser monetary value, etc. along with homemade alcohol like Mahua, Haandi, etc [5].

Talking about economic distribution, it has been noted that Indian consumers tend to go towards cheaper aides when it comes to alcohol consumption [6]. Treatment of these diseases will impose an economic burden of Rs 3127 billion on health system. Societal burden of alcohol including health system cost out of pocket expenditures and productive lose will be Rs 121,364 billion.

Therefore there will be an average loss of $1.45 \%$ of GDP per year to the Indian economy due to alcohol consumption [7]. It is also observed 3 to $45 \%$ of the total income of the house is spending on the alcohol. Alcohol consumption has led many families to be on roads and been debt. On one side country are developing due to alcohol taxes but on the other side. It is making individual in debt traps [8].

There are studies which have focused on the amount of alcohol consumption and it side effect but fewer attempts have been made on economic burden due to alcohol. Alcohol consumption creates an economic burden on the population. Since little is known about the economic burden of alcohol in India, this study will assess the economic burden of alcohol on the population.

\section{Objective}

To assess the economic burden of alcohol consumption among residents of Slum area of Belagavi city.

\section{Methodology}

A cross-sectional study was conducted in slum areas of Belagavi from $1^{\text {st }}$ August 2018 to $28^{\text {th }}$ February 2020. The sources of data were permanent resident of the slum area Belagavi city who consumes any kind of alcohol beverages. Data collection was done by using pre-designed and pretested questionnaire .Simple random sampling Technique was used for recruiting participants. Total participants were 154 , all the participants were male.

\section{- Inclusion Criteria:}

Age group above 18 years of age.

- Exclusion Criteria:

The participants who did not give inform consent.

\section{- Ethical Clearance:}

- Ethical clearance was obtained from the Institutional Ethics Committee for Human Subjects' Research of J. N. Medical College, Belagavi.

- Informed consent obtained from all the participants

\section{- Data Analysis:}

Data was entered in EXCEL, compiled and coded in SPSS version 20.

- $\quad$ Data analysis was done using SPSS version 20.

- Percentage, rates and ratio was calculated.

- Fisher's Exact Test used for comparison.

\section{Results}

A cross-sectional study was conducted among the age group above 18 years in Slum area Belagavi.

The socio-demographic characteristics of the study participants are presented where as in Table 1 maximum of the age group belonged to $30-39$ years which is 65 (42.2\%), followed by $41(26.6 \%)$ of the participants in the age group of $40-49$ years, and $1(0.6 \%)$ of the participant was in age group of 70 and above years. 134 (87\%) of the participants were Hindu, followed by Muslim and Christian who were $8.40 \%$ and $4.50 \%$ respectively. $86(56.8 \%)$ of the participant were living in Nuclear family and $68(44.2 \%)$ participant were living in joint family. 8 (5.2\%) participants were illiterate, $28(18.2 \%)$ participants had primary level schooling, $59(38.3 \%)$.

participants had completed secondary level, 39(25.3\%) participant had PUC level education and 20(13\%) participant were graduates. 71 (46.1\%), of participants were employed in private sector followed by $35.7 \%$ of them were business men, $10.4 \%$ were involved in agriculture, whereas $4.5 \%$ of them were in government services and $3.2 \%$ had other type of occupation. In our present study $58(37.66 \%)$ of the participants belonged to the lower middle class group, 43 (27.92\%) of the participants belonged to middle class group, $41(26.62 \%)$ of the participants belonged to upper middle class group, whereas 7 (4.54\%) and 5 (3.24\%) were from lower class and upper class group respectively (Table 2). Out of 154 participants, 46 (29.9\%) of the participant consume alcohol daily, 53 (34.4\%) of the participant consumes alcohol sometimes and $55(35.7 \%)$ of the participant consume 
alcohol once a week. Among the drinkers Whiskey 117 (76\%) was most commonly consumed, followed by Rum $27(17.5 \%)$, similarly Beer and Wine which is $9(5.8 \%)$, $1(0.6 \%)$ respectively consumed by the participants (Table 3 ). The mean age of alcohol consumption was $20.74 \pm 4.445$ years in the study participants. There was statistical association between socio-economic status and monthly amount spend on alcohol by the participants (majority people spent less than 2500 INR amount on alcohol) (P-Value $=<0.001$ Fisher's Exact Test $=31.358$ ) (Table 4$)$. Table no. 5 shows an association between socio-economic status and monthly amount spend on household expenses by the participants. (P- Value $=<0.001$ Fisher's Exact Test $=56.82$ ) .

\begin{tabular}{|c|c|c|}
\hline $\begin{array}{l}\text { Sociodemographic } \\
\text { variables }\end{array}$ & $f(N=154)$ & $-100 \%$ \\
\hline \multicolumn{3}{|l|}{ Age: } \\
\hline$<30$ & 30 & 19.5 \\
\hline $30-39$ & 65 & 42.2 \\
\hline $40-49$ & 41 & 26.6 \\
\hline $50-59$ & 14 & 9.1 \\
\hline $60-69$ & 3 & 1.9 \\
\hline$>70$ & 1 & 0.6 \\
\hline \multirow{3}{*}{$\begin{array}{l}\text { Religion: Hindu Muslim } \\
\text { Christian }\end{array}$} & 134 & 87 \\
\hline & 13 & 8.4 \\
\hline & 7 & 4.5 \\
\hline \multirow{2}{*}{ Type of family: Nuclear Joint } & 86 & 55.8 \\
\hline & 68 & 44.2 \\
\hline \multirow{5}{*}{$\begin{array}{c}\text { Educational status: Illiterate } \\
\text { Primary Secondary PUC } \\
\text { Graduate }\end{array}$} & 8 & 5.2 \\
\hline & 28 & 18.2 \\
\hline & 59 & 38.3 \\
\hline & 39 & 25.3 \\
\hline & 20 & 13 \\
\hline \multirow{5}{*}{$\begin{array}{l}\text { Occupational status: } \\
\text { Government Private service } \\
\text { Business Agriculture Others }\end{array}$} & 7 & 4.5 \\
\hline & 71 & 46.1 \\
\hline & 55 & 35.7 \\
\hline & 16 & 10.4 \\
\hline & 5 & 3.2 \\
\hline
\end{tabular}

Table 1: Distribution of study participants according to their socio-demographic profile.

The socio-demographic characteristics of study participants are presented in Table 1 . It shows that participants of this study belonged to age above 18 years, the maximum students $65(42.2 \%)$ were in age group of 30-39 years, followed by 41 ( $26.6 \%$ ) in age group of $40-49$ years,
$30(19.5 \%)$ in age group of $<30$ years, $14(9.1 \%)$ in age group of $50-59$ years , $3(1.9 \%) 60-69$ years and $1(0.6 \%)$ above 70 years. among 154 maximum participants $134(87 \%)$ were Hindus, 13(8.4\%) were Muslims and 7(4.5\%) were Christians. $86(55.8 \%)$ belonged to nuclear family and $68(44.2 \%)$ to joint family. Regarding educational status, $8(5.2 \%)$ were illiterate, $28(18.2 \%)$ had completed primary education, 59(38.3\%) secondary education, 39(25.3\%) PUC and 20(13\%) were graduated. In the present study the participants working in Government sector were 7(4.5\%), private service 71(46.1), business 55(35.7\%), the participants practicing agriculture were $16(10.4 \%)$ and participants with other occupations were $5(3.2 \%)$.

\begin{tabular}{|c|c|}
\hline Social Class & Percentage\% (N-154) \\
\hline lower class & $4.54 \%(7)$ \\
\hline lower middle class & $37.66 \%(58)$ \\
\hline middle class & $27.92 \%(43)$ \\
\hline upper middle class & $26.62 \%(41)$ \\
\hline upper class & $3.24 \%(5)$ \\
\hline Total & 100 \\
\hline
\end{tabular}

Table 2: Socio-economic Classification of the participants.

Above table shows, majority 58 (37.66\%) of the participants belong to the lower middle class group, 43 (27.92\%) of the participants belong to middle class group, $41(26.62 \%)$ of the participants belong to upper middle class group, whereas 7 (4.54\%) and $5(3.24 \%)$ belong to lower class and upper class group respectively.

\begin{tabular}{|c|c|c|}
\hline Particular & $\mathbf{f ~ ( N = ~ 1 5 4 ) ~}$ & \% (N=100) \\
\hline \multirow{3}{*}{$\begin{array}{c}\text { Alcohol consumption: Daily } \\
\text { Sometimes }\end{array}$} & 46 & 29.9 \\
\cline { 2 - 3 } & 53 & 34.4 \\
\cline { 2 - 3 } & 55 & 35.7 \\
\hline \multirow{3}{*}{$\begin{array}{c}\text { Type of alcohol: Beer Wine } \\
\text { Rum Whiskey }\end{array}$} & 9 & 5.8 \\
\cline { 2 - 3 } & 1 & 0.6 \\
\cline { 2 - 3 } & 27 & 17.5 \\
\hline
\end{tabular}

Table 3: Distribution of participants according to alcohol and type of alcoholic beverage consumption.

The Table 3 shows among the total participants 46(29.9\%) participants consumed alcohol daily, similarly 53(34.4\%) consumed alcohol sometimes, 55(35.7\%) once a week. 9(5.8\%) consumed Beer, 1(0.6\%) Wine, 27(17.5\%) Rum and maximum participants $117(76 \%)$ consumed Whiskey. 


\begin{tabular}{|c|c|c|c|c|c|c|c|c|}
\hline & & $\begin{array}{l}\text { lower } \\
\text { class }\end{array}$ & $\begin{array}{l}\text { lower middle } \\
\text { class }\end{array}$ & $\begin{array}{l}\text { middle } \\
\text { class }\end{array}$ & $\begin{array}{l}\text { upper middle } \\
\text { class }\end{array}$ & $\begin{array}{c}\text { upper } \\
\text { class }\end{array}$ & Total & \\
\hline \multirow{8}{*}{$\begin{array}{l}\text { Amount } \\
\text { spend in } \\
\text { alcohol per } \\
\text { month }\end{array}$} & $<2500.00$ & 6 & 41 & 33 & 31 & 2 & 113 & \multirow{7}{*}{$\begin{array}{c}\text { P- value= } \\
<0.001 \\
\text { Fisher's } \\
\text { Exact Test }= \\
31.358\end{array}$} \\
\hline & $2500.00-3749$ & 1 & 10 & 6 & 4 & 0 & 21 & \\
\hline & $3750.00-4999$ & 0 & 2 & 3 & 3 & 0 & 8 & \\
\hline & $5000.00-6249$ & 0 & 4 & 0 & 2 & 1 & 7 & \\
\hline & $6250.00-7499$ & 0 & 0 & 1 & 0 & 0 & 1 & \\
\hline & $7500.00-8749$ & 0 & 1 & 0 & 0 & 2 & 3 & \\
\hline & 10000 & 0 & 0 & 0 & 1 & 0 & 1 & \\
\hline & above & & & & & & & \\
\hline \multicolumn{2}{|c|}{ Total } & 7 & 58 & 43 & 41 & 5 & 154 & \\
\hline
\end{tabular}

Table 4: Association between socio-economic status and monthly amount spend in alcohol.

Table 4 shows an association between socio-economic status and monthly amount spend on alcohol by the participants. It is seen that there is a significant association between socio- economic status and monthly amount spend on alcohol by the participants. (P- Value $=<0.001$ Fisher's Exact Test $=31.358$ ).

\begin{tabular}{|c|c|c|c|c|c|c|c|c|}
\hline & & $\begin{array}{c}\text { lower } \\
\text { class }\end{array}$ & $\begin{array}{c}\text { lower } \\
\text { middle class }\end{array}$ & $\begin{array}{l}\text { middle } \\
\text { class }\end{array}$ & $\begin{array}{c}\text { upper } \\
\text { middle class }\end{array}$ & $\begin{array}{l}\text { upper } \\
\text { class }\end{array}$ & & \\
\hline \multirow{7}{*}{$\begin{array}{l}\text { Monthly expense } \\
\text { s of household }\end{array}$} & $<3000.00$ & 1 & 0 & 0 & 0 & 0 & 1 & \\
\hline & $3000.00-5999$ & 4 & 13 & 6 & 0 & 0 & 23 & \\
\hline & $6000.00-8999$ & 2 & 19 & 20 & 9 & 3 & 53 & \\
\hline & $9000.00-11999$ & 0 & 15 & 3 & 13 & 0 & 31 & $\begin{array}{c}\text { P- value }=<0.001 \\
\text { Fisher's Exact } \\
\text { Test }=56.82\end{array}$ \\
\hline & $12000.00-14999$ & 0 & 5 & 6 & 9 & 1 & 21 & \\
\hline & $15000.00-17999$ & 0 & 4 & 6 & 5 & 1 & 16 & \\
\hline & 18000.00 above & 0 & 2 & 2 & 5 & 0 & 9 & \\
\hline \multicolumn{2}{|c|}{ Total } & 7 & 58 & 43 & 41 & 5 & 154 & \\
\hline
\end{tabular}

Table 5: Association between socio-economic status and monthly amount spend in Household.

Table 5 shows an association between socio-economic status and monthly amount spend on household expenses by the participants. It is seen that there is a significant association between socio-economic status and monthly amount spend on household expenses by the participants. $(\mathrm{P}-$ Value $=<0.001$ Fisher's Exact Test $=56.82)$.

\section{Discussion}

In the present study it is seen that $73.37 \%$ of the participant spend less than 2500 INR in alcohol per month. A study in Vietnam reveled that USD3.5 is spent by individual in alcohol per month [9].

In the present study it is seen that majority $35.7 \%$ of the participant consume alcohol once a week where they consume approximately 3 glasses. In this study it is seen that maximum participants prefer Whiskey (76\%). A similar study was conducted in Bangalore, which also revealed similar finding where whiskey (48.6\%) was consumed more and also majority was in slum area than in rural or burden [10].

In a study conducted in Europe on economic burden of alcohol consumption shows that the directed cost range was $€ 1591-€ 7702$ which was spent on individual hospitalization. Similar study was conducted in Germany in primary health care where more than $€ 1836$ was spend on alcoholic Patient in 6 month. The study confirms that economic burden is associated with alcohol dependence [4].

In present study it is seen that maximum of the 
participants belongs to lower middle class group (37.66\%) where the participants spend around 6000-8999 INR (34.41\%) monthly in household expenses by individual, similarly it is seen that less than 2500 INR is spend in alcohol by individual in a month. The finding of the present study shows an association between socio- economic status and monthly amount spend on alcohol by the participants. It also shows then association between socio-economic status and monthly amount spend on household expenses by the participants. As it shows that economic burden of alcohol consumption is more in lower middle class group people compare to others.

Due to alcohol consumption the people face different type of economic burden among which $89.2 \%$ population always face the economic problem and $0.4 \%$ population never face the economic problem [2].

\section{Conclusion}

The study concludes that alcohol consumption is a economic burden as almost $25 \%$ of the total income is spent on alcohol consumption as compared to other household expenses. This leads to increased expenditure on health as alcohol is directly related to health. There is a need of awareness programme on alcohol consumption with economic burden should be held in slum areas.

\section{Acknowledgement}

I thank teaching staff in Department of Public Health for their guidance and support.

\section{References}

1. Rehm J, Samokhvalov AV, Shield KD (2013) Global burden of alcoholic liver diseases. Journal of hepatology 59(1): 160-108.
2. Abat C, Roussel Y, Chaudet H, Raoult D (2020) Alcohol and the global burden of disease.

3. Jakovljevic M, Varavikova EA, Walter H, Wascher A, Pejcic AV, et al. (2017) Alcohol beverage household expenditure, taxation and government revenues in broader European WHO region. Frontiers in pharmacology 8: 303.

4. Venkataraman S, Anbazhagan S, Anbazhagan S (2019) Expenditure on health care, tobacco, and alcohol: Evidence from household surveys in rural Puducherry. Journal of Family Medicine and Primary Care 8(3): 909913.

5. Kumar S (2017) Price elasticity of alcohol demand in India. Alcohol and alcoholism 52(3): 390-395.

6. Thavorncharoensap M, Teerawattananon Y, Yothasamut J, Lertpitakpong C, Thitiboonsuwan K, et al. (2010) The economic costs of alcohol consumption in Thailand, 2006. BMC Public Health 10(1): 323.

7. Thavorncharoensap M, Teerawattananon Y, Yothasamut J, Lertpitakpong C (2009) The economic impact of alcohol consumption: a systematic review. Substance abuse treatment, prevention, and policy 4(1): 20.

8. Laramee P, Kusel J, Leonard S, Aubin HJ, François C, et al. (2013) The economic burden of alcohol dependence in Europe. Alcohol and alcoholism 48(3): 259-269.

9. Manthey J, Laramee P, Parrott S, Rehm J (2016) Economic burden associated with alcohol dependence in a German primary care sample: a bottom-up study. BMC public health 16(1): 906.

10. Pillai A, Nayak MB, Greenfield TK, Bond JC, Nadkarni A, et al. (2013) Patterns of alcohol use, their correlates, and impact in male drinkers: a population-based survey from Goa, India. Social psychiatry and psychiatric epidemiology 48(2): 275-282. 